\title{
Catching Liars: Why it can be so Hard
}

\section{Shawn Adair Johnston}

Forensic Psychologist, Oregon, USA

Corresponding author: Shawn Adair Johnston, Forensic Psychologist, Oregon City, USA, Tel: 5033444429; E-mail: shawnjohnstonphd@comcast.net

Received date: September 20, 2016; Accepted date: January 05, 2017; Published date: January 09, 2017

Copyright: () 2017 Johnston SA. This is an open-access article distributed under the terms of the Creative Commons Attribution License, which permits unrestricted use, distribution, and reproduction in any medium, provided the original author and source are credited.

\begin{abstract}
Considerable research reveals that most people, including mental health and law enforcement professionals, are remarkably poor at catching liars, doing no better than chance. Our comparative inability to detect deception poses a profound threat to the reliability of forensic psychological and psychiatric evaluations of criminal defendants intended to assess such things as current mental status and future dangerousness. In forensic evaluations, where one's personal freedom, even life, can be at stake, some clients, perhaps more than some, will inevitably dissemble. This essay provides a brief and non-technical description of the research my students and we have conducted designed to better understand the reasons for which detecting deception is so difficult. In this regard, and consistent with much previous research, we discovered that in assessing the verbal content of other persons' statements, it is possible with a good degree of reliability to differentiate between true and deceptive statements of criminal defendants. We also found that the "truth" is itself a multidimensional concept and that truthful versus false statements differ with regard to both the quantity and quality of information contained in a statement. While multiple challenges exist to accurately detect deception, our data strongly suggested that it may be so difficult to catch liars because it requires more cognitive work to identify false rather than true statements. Indeed, the data indicate that determining a statement is true appears to involve a one-step cognitive process while determining a statement is false appears to involve a two-step cognitive process, whereby a false statement is recognized as lacking attributes of truthfulness while simultaneously manifesting attributes of deception. That it would be more difficult to recognize falsehoods and require more cognitive work does not seem surprising considering that the identification of a lie forces us to look below and reject the surface meaning of a statement concluding that the statement is not simply inaccurate but actually intended to deceive or mislead us. On a more positive note, even though deception is ubiquitous in human relationships and a significant number of dangerous liars will be successful, the accuracy of deception detection can be improved by the application of the findings from verbal content analysis identifying those statement attributes characteristic of truthfulness versus deception. It would seem especially important for forensic psychologists and psychiatrists to be aware of research capable of assisting them in assessing the veracity of criminal defendants participating in court-ordered evaluations.
\end{abstract}

Keywords: Forensic psychology; Deception detection; Verbal content analysis; Dangerousness assessment; Sex offenders; Insanity

\section{Short Communication}

Few things are more important to the reliability of a forensic psychological or psychiatric evaluation than determining if the client is lying. Consider one of the most frequently court ordered forensic evaluations: assessing for the judge whether a convicted child molester is so dangerous and so likely to reoffend, that he cannot be allowed to remain in the community instead of being sent to prison. How many convicted molesters do you believe would be completely candid to a court ordered forensic psychologist or psychiatrist with regard to their feelings of sexual attraction towards children? How many convicted molesters do you believe would be totally truthful about their sexual urges towards children knowing that their truthfulness could get them sent to prison? Another typical forensic evaluation involves assessing whether a criminal defendant was legally insane at the time they committed some alleged offense (i.e., at the time they committed the crime, did they know what they were doing and could they distinguish right from wrong?). Defendants who are found "not guilty by reason of insanity" are likely to spend less time locked up than defendants judged sane. Just as important, the defendant found insane does his time in a state hospital, not prison, which usually involves doing time in a far more palatable and less dangerous place. Do you think that a defendant undergoing a sanity evaluation might be tempted to exaggerate or even make up psychotic symptoms as a way of trying to be found insane? To put the point simply, in forensic evaluations, where personal freedom, money or child custody may be at stake, some, perhaps more than some, people will lie through their teeth to try to get the forensic report they want. While client deception in traditional psychotherapy or psychological evaluations may be relatively rare, in forensic evaluations client deception is absolutely inevitable and the forensic psychologist or psychiatrist who does such assessments has both a practical and ethical responsibility to do everything in his/her power to identify and, if appropriate, confront deceptive clients.

Unfortunately, decades of research indicate that forensic psychologists and psychiatrists are generally rather poor at detecting liars. Indeed, the empirical research is positively depressing: people in general, including judges, jurors, police officers, psychologists and psychiatrists catch liars no more than about half the time [1-7]. Have you ever wondered why so many confidence men and con artists seem to flourish? Have you wondered how the savings and loan fiasco of the 80's or the housing bubble of 2007 could have happened with absolutely no one going to jail for the extraordinary amount of criminal fraud perpetrated in both situations? Lying is, of course, ubiquitous among human beings and none of us is completely clean in 
this regard $[4,8]$. There are, however, a small percentage of truly dangerous persons from whom you can lose your money or even your life if they successfully ensnare you in their deception. We suspect you can think of multiple times in your life when you wish you had been sharper at catching liars. Why is it so hard to do so?

For the past five years, we at Portland State University in Oregon have been focusing on this question. In this short paper, we will provide a non-technical description of the results of our research and what our research tells us about why it is so difficult to detect liars.

The first thing to note is what is called the "truth bias". This refers to the fact that the overwhelming majority of things we say to each other is true $[6,9]$. To be sure, organized society would not even be possible if most of us lied to each other most or all of the time. Speaking the truth is the normal or typical form of communication; lying, though universal, and although we all do it to a greater or lesser degree, is still the aberration.

Beyond the truth bias, calling or labeling someone a liar is serious business and can get the accuser attacked or even killed. In addition, we are "socialized" to focus our attention on the wrong thing when it comes to detecting liars. For example, physically attractive people or people with high social status are viewed as being more honest or trustworthy than unattractive or lower status persons. Of particular importance, we are encouraged by folk wisdom to focus on signs of nervousness or anxiety which are believed to be emblematic of lying. It is, in fact, signs of nervousness as measured by increases in heart rate, respiration and blood pressure that is the basis of the polygraph or so called lie detector test. As it turns out, most research indicates that signs of nervousness indicate the person being observed is nervous, not necessarily telling a lie. Imagine being completely innocent but hauled into an interview room at your local police station and investigated for the murder of your next door neighbor. If you were just sitting at home by yourself the night of the murder, thereby having no alibi, do you think you might break into a cold sweat when you start to be queried regarding your whereabouts at the time? In other words, you can be nervous because you are guilty or because you are innocent. Beyond this, we also know that an experienced psychopath can look you in the eye and tell a lie without flinching. Signs of nervousness are just that - signs of nervousness.

A more complex explanation for failing to catch liars coming out of our research suggests that it is easier for people to determine when a statement is true rather than when it is false $[10,11]$. This is connected with the theory of "cognitive load" which asserts that telling a successful lie can be mentally challenging in that the liar must be able to remember their lie and avoid the kind of inconsistencies or contradictions that can expose their deception. Similarly, for the observer, detecting a lie requires more mental work than assuming a statement is true since it necessitates that you see below the surface meaning of a person's words in order to recognize the underlying falsehood. In detecting a lie, you have to understand what someone has said to you but then go on to assess it as false. This is clearly more mentally challenging than assuming what is said is true and simply continuing in your conversation.

With regard to the greater cognitive work required to recognize false rather than true statements, one of the most interesting findings in our research reveals that judging a statement as true appears to involve a single cognitive act while judging that a statement is false appears to involve a two-step cognitive process [11]. Specifically, our research, conducted with over 300 upper division students at Portland State
University in Oregon (mostly psychology majors), indicates that determining something is true involves nothing other than concluding it sounds or appears true (e.g., the statement contains only attributes or characteristics indicative of truthfulness). On the other hand, determining something is false appears to involve the decision that the statement lacks truthfulness and indicates falseness. For example, when child molesters lie about their criminal sexual behavior, their lies are typically devoid of truthful information while abounding with false information. When asked, for example, to provide their version of events relative to specific accusations of abuse made by a victim, the molesters' statements typically lack detail and are totally vague (absence of attributes of truthfulness) while, at the same time, their explanation for why they have been falsely accused is often incredible if not outright preposterous (presence of attributes of deception).

A great deal of research regarding deception detection reveals that one of the primary hallmarks of true statements is the presence of specific details such as the physical space in which something occurred, the time it occurred, the things and persons present when it occurred and the relationships between the different things and persons present $[6,12,13]$. True statements contain this kind of rich and varied detail and it is the explicit absence of such attributes of truthful statements that are so often apparent in the lies of child molesters as well as other types of liars.

On the other hand, in addition to an absence of attributes of truthfulness, typical lies told by molesters sound patently false. It is commonplace for molesters to claim they have been falsely accused of sexually abusing a child because they have been overly generous or kind to the victim. As absurd as it may sound, many molesters claim to be the victims of false criminal allegations because they were "just too nice". It is the presence of this kind of obviously false statement, in combination with the absence of information characteristic of truthfulness that often exposes the deception of all sorts of liars.

We have also found that true statements, indeed the truth itself, are multi rather than one-dimensional. Our research findings strongly suggest that the truthfulness of a statement contains, at a minimum, the two general characteristics just alluded to above: the richness and quantity of details contained in the statement and the quality of the content contained in the statement. With regard to detail quantity, we found clarity of details (pertaining to the variety and richness of information contained in the statement), spatial information (pertaining to where things or people were located), temporal information (pertaining to when things happened), perceptual information (pertaining to such things as smell, taste and touch), contextual information (pertaining to the relationship or connection between persons and things) to all play a significant role in separating between truthful and deceptive statements. Statement quality, on the other hand, was defined by realism (how believable was the statement), reconstructability, (how coherent or logically interconnected the statement was), and relevance (how pertinent was the information contained in the statement). Interestingly, our research indicates that when we make judgments as to whether a statement is true or false, we overwhelmingly rely on the use of a single variable, namely how realistic we believe the statement to be $[10,11]$. However, with regard to whether a statement is factually or objectively true or false, the realism, reconstructability, spatial and temporal information variables were all roughly equal in distinguishing between actually true or false statements. In other words, while we may focus on the single most important attribute of truthfulness, statement realism, we are ignoring a whole pack of other factors, all of which have been shown to be 
reliable in differentiating between true and false statements. We believe these findings provide direct insight into the question of why we are so poor at catching liars.

Our research, as well as some previous work, leads to the rather counterintuitive idea that the indirect assessment of truthfulness may be superior to and more reliable than, the direct assessment of truthfulness $[8,14]$. Brinke et al. have presented data, for example, which suggests that the assessment of another person's truthfulness might be more accurate when, instead of directly answering the question as to whether we think the other person is being truthful or deceptive, we are asked to rate the other person along a variety of different dimensions such as their apparent openness, honesty, sincerity, etc. This has led some social scientists to speculate that our evolutionary history has endowed us with a semi or even unconscious capacity to identify those persons and situations in which we are being deceived.

Alas, our research flies in the face of such a soothing notion that our ancient prehistory has psychically armored us against liars. Could the savings and loan scandal or the financial fraud causing the great recession have occurred if we possessed such protection? Indeed, if we possessed such a protective mental architecture, serial killers, child molesters, dishonest used car salesmen, confidence men and hucksters of all sorts would rarely be successful. Unfortunately, they are often successful and there is not the slightest indication that future human beings will be any better at catching liars than we are. Why?

In addition to what we have already discussed, the truth bias and the greater difficulty in identifying false versus true statements, almost all of us make rapid, intuitively appealing and more often than not, correct judgments that what we are being told is true. Remember the vast majority of what people say to you is true, so that if you simply assumed everything said to you was true, you would be right the majority of the time. It is precisely because false statements are the aberration, the exception to the rule that this kind of simplistic heuristic would inevitably lead to us being successfully deceived on a regular basis.

As noted above, though, we are not quite so defenseless in that we do appear to apply the criterion of realism when we have concerns regarding the truthfulness of what we are being told. This does not; however, appear to get us beyond about the fifty/fifty situation in determining when someone is lying to us. Our research, as well as that of many others $[6,11,12]$, indicates that accuracy of deception detection can be increased when we take into account the kind of detail quantity and statement quality variables described above. Now admittedly it could be a bit awkward if you are evaluating the truthfulness of someone's proclamation of love for you by pulling out a form where you rate their statement in terms of its realism, reconstructability, relevance, spatial, temporal, contextual and perceptual information. After all, the great thing about using the realism heuristic to determine if what you have been told is true or false is that it is quick and easy. The bad thing is that, if it is a lie, you will probably miss it.

In sum, while we might not recommend that you subject the statements of your next real estate agent or political candidate to a multidimensional analysis based on the factors defining the detail quantity and content quality of their statements, this might be a good idea if you are a forensic psychologist or psychiatrist evaluating a potentially dangerous criminal offender for the court. If it is the truthfulness of your prospective date or a possible real estate agent you are evaluating, it would most definitely not hurt to keep these variables in the back of your mind since if you can assess their statements along more variables than just realism, you increase the likelihood of detecting a lie. If, on the other hand, you are a court appointed forensic examiner, basing your evaluation on empirically derived variables would appear to be consistent with the ethical standards of integrity and beneficence, while providing the court with the most accurate forensic assessment possible.

\section{Conclusion}

While one of the single greatest threats to the reliability of a courtordered forensic psychological or psychiatric evaluation of a criminal defendant is potential client deception, there is increasing research literature indicating that the verbal content analysis of the client's statements can enhance the accuracy of deception detection. The research focusing on deception detection is primarily concerned with the types of information contained in statements which have been shown to indicate truthfulness versus deception. Considerable work indicates, for example, that statements which contain greater variety and richness of detail, including details regarding spatial, temporal, contextual and perceptual information are more likely to be true. Similarly, statements including information which is more realistic, relevant and logically coherent or plausible are more likely to be true. While most people focus only on the assessment of realism in trying to determine if a statement is true or false, our work strongly implies that the realism of a statement is only one of the important attributes of truthfulness and that other variables such as the richness and variety of the details included are just as important. In all, there exists an expanding research literature capable of providing forensic psychologists and psychiatrists with a theoretically compelling and empirically based method for identifying client deception. Verbal content analysis is, of course, only one technique available to the forensic examiner in assessing the veracity of potentially dangerous clients. Given the extraordinary importance of such court ordered forensic evaluations and the obvious threat to the reliability of these evaluations, it is hoped that the use of verbal content analysis can provide the forensic examiner with one more tool capable of enhancing their ability to provide the judicial system with the most accurate reports possible.

\section{References}

1. Akehurst L, Kohnken G, Vrij A, Bull R (1996) Lay persons' and police officers' beliefs regarding deceptive behaviour. Appl Cogn Psychol 10: 461-471.

2. Bond CF, DePaulo BA (2008) Individual differences in judging deception: Accuracy and bias. Psychol Bull 134: 477-492.

3. Bond CF Jr, DePaulo BM (2006) Accuracy of deception judgments. Pers Soc Psychol Rev 10: 214-234.

4. DePaulo B (2010) The hows and whys of lies.

5. Ekman P, O'Sullivan M (1991) Who can catch a liar? Am Psychol 46: 913-920.

6. Ten Brinke L, Porter S (2013) Discovering deceit: Applying laboratory and field research in the search for truthful and deceptive behavior. In Cooper B, Griesel D, Ternes M (Eds.) Applied issues in investigative interviewing, eyewitness memory, and credibility assessment, Springer, NewYork, USA pp: 221-235.

7. Vrij A, Edward K, Bull R (2001) Police officers' ability to detect deceit: The benefit of indirect deception detection measures. Legal Criminol Psych 6: 185-196. 
8. Trivers R (2011) The folly of fools: The logic of deceit and self-deception in human life. Basic Books, New York, USA.

9. De Waal FBM (1996) Good Natured. Harvard University Press, London.

10. Johnston SA, Candelier AS, Powers-Green D, Rahmani S (2014) Attributes of Truthful Versus Deceitful Statements in the Evaluation of Accused Child Molesters. Sage Open 4: 1-10.

11. Johnston S, Candelier A, Powers-Green D, Johnston G (2016) Attributes of True and Deceptive Statements Made in Evaluations of Criminal Defendants. J Forensic Psychol Pract 16: 347-373.
12. Nahari G, Vrij A, Fisher RP (2012) Does the Truth Come out in the Writing? SCAN as a Lie Detection Tool. Law Hum Behav 36: 68-76.

13. Vrij A, Akehurst L, Soukara S, Bull R (2004) Let Me Inform You How to Tell a Convincing Story CBCA and Reality Monitoring Scores as a Function of Age, Coaching, and Deception. Can J Behav Sci 36: 113-126.

14. Ten Brinke L, Stimson D, Carney DR (2014) Some Evidence for Unconscious Lie Detection. Psychol Sci 25: 1098-1105. 